ISSN 2236-0859

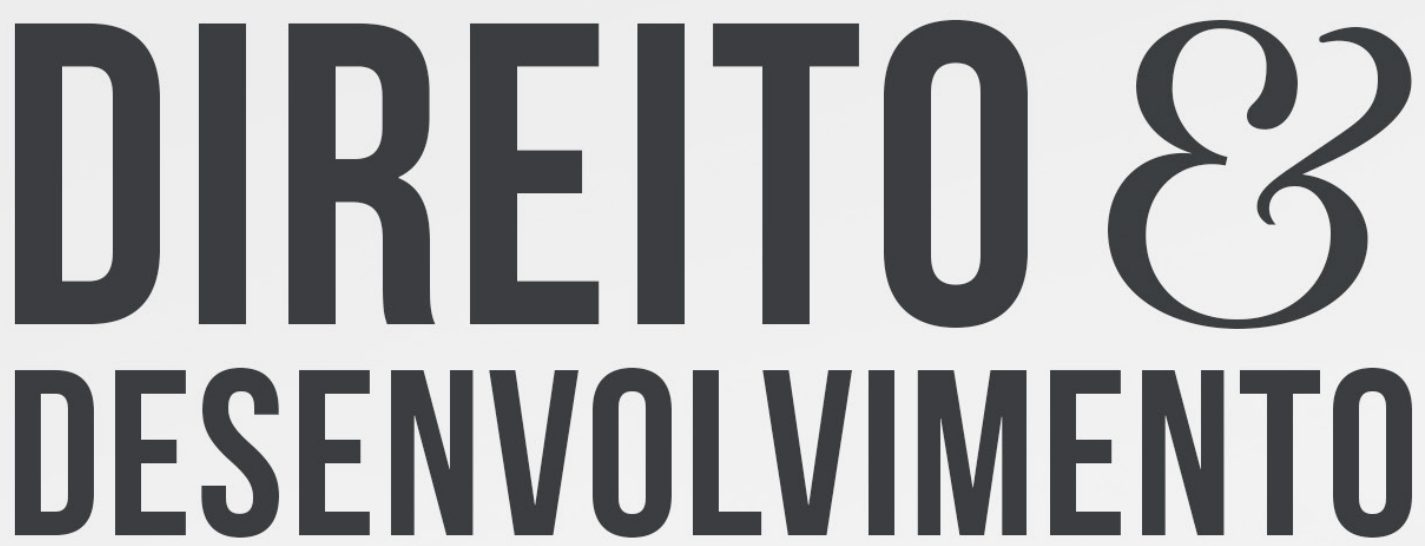

REVISTA DO PROGRAMA DE PÓS-GRADUAÇÃO EM DIREITO MESTRADO EM DIREITO E DESENVOLVIMENTO SUSTENTÁVEL

A RESPONSABILIDADE DO PROPRIETÁRIO POSSUIDOR INDIRETO PELOS DANOS CAUSADOS AO MEIO AMBIENTE DO TRABALHO PELO POSSUIDOR DIRETO: UMA ANÁLISE CIENTIFFICA DA JURIDICIDADE DA IMPUTAÇÃO OBJETIVA PELA TEORIA DO RISCO INTEGRAL

MARCELO SANTORO DRUMMOND ELCIO NACUR REZENDE 


\title{
A RESPONSABILIDADE DO PROPRIETÁRIO POSSUIDOR INDIRETO PELOS DANOS CAUSADOS AO MEIO AMBIENTE DO TRABALHO PELO POSSUIDOR DIRETO: UMA ANÁLISE CIENTÍFICA DA JURIDICIDADE DA IMPUTAÇÃO OBJETIVA PELA TEORIA DO RISCO INTEGRAL
}

\section{THE RESPONSIBILITY OF THE OWNER INDIRECT POSSESSOR FOR THE DAMAGE CAUSED TO THE ENVIRONMENT BY THE DIRECT POSSESSOR: A SCIENTIFIC ANALYSIS OF THE LEGALITY OF THE OBJECTIVE IMPUTATION BY THE THEORY OF FULL RISK}

Recebido: 08/11/2019

Aprovado: 12/12/2019
Marcelo Santoro Drummond ${ }^{1}$ Elcio Nacur Rezende ${ }^{2}$

RESUMO:

O artigo aborda a possibilidade de responsabilidade civil do proprietário em virtude de locação ou arrendamento de imóvel destinado a atividade empresarial e os danos ao meio ambiente do trabalho. Os objetivos são analisar as hipóteses de eventual responsabilização do proprietário, possuidor indireto, além da apresentação dos seus limites, bem como a aferição de qual teoria alusiva à responsabilidade civil seria a mais adequada e também as hipóteses de eventual exclusão de culpa do proprietário. Os resultados obtidos denotam a atribuição de responsabilidade civil ao proprietário, em face de eventual dano decorrente do imóvel objeto de contrato, nas hipóteses nas quais tenha concorrido, direta ou indiretamente, para o surgimento do dano. Far-se-á uso da abordagem qualitativa e do método hipotético-dedutivo, a partir da análise legislativa e doutrinária do tema.

Palavras-chave: Meio Ambiente do Trabalho. Propriedade. Posse Indireta. Responsabilidade civil. Danos ambientais.

\begin{abstract}
:
The article discusses the possibility of civil liability of the owner due to lease or rental of property intended for business activity and the damage it may cause to the work environment. The objectives are to analyze the hypothesis of eventual liability of the owner, indirect possessor, as well as the presentation of its limits, and the measurement of which theory referring to the civil liability would be the most appropriate and also analyzing the hypothesis of exclusion of the owner's fault. The results show the attribution of civil liability to the owner, in the face of any 1 Doutorando em Direito Ambiental pela Escola Superior Dom Helder Câmara. Mestre em Direito pela Pontifícia Universidade Católica de Minas Gerais. Advogado. Email: djowe@uol.com.br

2 Doutor e Mestre em Direito pela Pontifícia Universidade Católica de Minas Gerais. Professor dos Programas de Pós-graduação em Direito da Escola Superior Dom Helder Câmara e das Faculdades Milton Campos. Procurador da Fazenda Nacional. Email: elcionrezende@yahoo.com.br
\end{abstract}


damage resulting from the property under contract, in the hypothesis in which it has directly or indirectly contributed to the damage. The qualitative approach and the hypothetical-deductive method will be used, based on the legislative and doctrinal analysis of the theme.

Keywords: Work Environment. Property. Indirect Possession. Civil Liability. Environment Damages.

\section{INTRODUÇÃO}

O direito a um meio ambiente justo e equilibrado emerge como direito fundamental a partir da interpretação sistemática e finalística de diversos preceitos contidos na Constituição da República de 1988.

É concebido como um direito de terceira geração, sendo chancelado pela atual doutrina e jurisprudência pátria.

Sabe-se que a construção e alcance do meio ambiente partem de uma visão complexa, atingindo os mais diversos aspectos da vida humana, bem como da natureza, restando, indubitavelmente nele inserido, o meio ambiente do trabalho.

Assim como o meio ambiente natural, artificial e cultural, o meio ambiente do trabalho emerge como parte relevante de um todo, de uma construção que revela o amplo alcance atinente ao meio ambiente.

E nesse sentido, as proteções constitucionais e infra constitucionais chanceladas pelo ordenamento jurídico pátrio alcançam, sem sombra de dúvida, o meio ambiente laboral.

É sabido também que no contexto de uma sociedade de risco, onde o ser humano é potencial criador de riquezas, emergindo notórios riscos derivados das mais diversas atividades econômicas por ele desenvolvidas, o meio ambiente laboral também é alvo das ações humanas. Assim, também é alvo de degradação, que ocorre sob diversos aspectos a serem estudados no presente artigo, que podem ter como efeitos danos que remontam notória reparação.

E o exercício da atividade empresarial nem sempre ocorre em um ambiente físico pertencente ao empregador, na medida em que este é mero possuidor direto, na medida em que firma um contrato de locação com o proprietário do bem no qual se instala o empreendimento.

E na medida em que ocorrem danos ambientais, derivados da exploração do referido bem imóvel, verifica-se a necessidade de responsabilização do agente pela prática do dano.

Justifica-se o presente artigo pela necessidade de se delimitar as hipóteses de inserção do proprietário nos atos que envolvem o dano ao meio ambiente do trabalho, bem como o apontamento dos eventuais limites de sua responsabilidade, levando-se em consideração as hipóteses fáticas inerentes à locação do bem destinado à atividade laboral.

Daí o objetivo central de apontar os limites, hipóteses e alcance de eventual responsabilidade civil do proprietário, seja ele o locador ou arrendador, ou seja, mero possuidor indireto. Tal análise se baseará nos estudos acerca da função social da propriedade, bem como das teorias que envolvem a responsabilidade objetiva, em especial, sopesando-se as teorias do risco integral e risco criado, bem como na hipótese de se poder atribuir responsabilidade solidária por danos causados ao meio ambiente do trabalho.

Daí se apresentam os seguintes problemas: seria viável a responsabilidade rígida, objetiva, derivada do risco integral, ao proprietário não possuidor direto? Seria possível a atribuição de uma responsabilidade solidária do proprietário, ante a inércia do causador direto do dano? E quais os critérios para a atribuição de eventual responsabilidade? 
Para a consecução dos propósitos aqui traçados, será utilizado como instrumento de pesquisa a abordagem qualitativa, a partir da explicação acerca do meio ambiente do trabalho como sujeito de proteção ambiental constitucional, como direito fundamental. Será utilizado o método hipotético-dedutivo buscando uma análise axiológica do contexto justrabalhista a partir da relação entre direitos e deveres do proprietário e os efeitos de seus atos e omissões. $\mathrm{O}$ referencial teórico adotado foi Guilherme José Purvin de Figueiredo, que aborda a propriedade como instrumento de proteção ambiental.

\section{O MEIO AMBIENTE DO TRABALHO COMO SUJEITO DE PROTEÇÃO CONSTITUCIONAL - A RESPONSABILIDADE DO EMPREGADOR EM FACE DO MEIO AMBIENTE LABORAL}

O direito ao meio ambiente do trabalho justo e equilibrado, assim compreendido como parte de todo um conjunto sistematizado e constitucionalmente protegido, que diz respeito ao Direito Ambiental, é traduzido a partir da necessidade de se garantir ao ser humano empregado condições dignas e equilibradas de trabalho.

E tais garantias emergem tanto no que concerne ao meio ambiente laboral stricto sensu, ou seja, o ambiente físico no qual exerce sua atividade o trabalhador, bem como sob o aspecto subjetivo, no tocante às condições contratuais que asseguram o labor digno, não estafante, permitindo ao empregado a manutenção de um ideal estado de saúde físico e mental, este definido como o meio ambiente do trabalho imaterial, que se exemplifica pelos critérios de estabelecimento de limites de jornada, intervalos, períodos de descanso, bem como da ingerência ou não do empregador no tempo livre a disposição do trabalhador.

Cumpre aqui trazer a abalizada definição de meio ambiente do trabalho a partir da concepção de Guilherme José Purvin de Figueiredo, que assim dispõe:

\footnotetext{
Por meio ambiente do trabalho devemos entender não apenas um espaço físico determinado (por exemplo, o espaço geográfico ocupado por uma indústria), aquilo que costumeiramente denominamos de estabelecimento, mas a conjugação do elemento espacial com a ação laboral. Hoje, a maioria dos trabalhadores insere-se em conglomerados urbanos, labutando no interior das indústrias, escritórios, hospitais, supermercados, escolas, etc. Nessas situações, a fixação do trabalhador em determinado local se dá de forma tão clara que não haveria necessidade de se distinguir a noção de meio ambiente de trabalho (local onde o trabalhador está desenvolvendo a sua atividade profissional) da noção de estabelecimento, por serem coincidentes ao menos enquanto o estabelecimento for o palco da ação laboral. A rigor, essa coincidência somente se dá no momento em que o trabalhador está exercendo as suas atividades profissionais. Um estabelecimento industrial que venha a ser interditado por um motivo qualquer continuará a ser um estabelecimento, mas não pode ser chamado de meio ambiente de trabalho. (FIGUEIREDO, 2010, 193-194)
}

Vale aduzir que o presente estudo se concentrará na análise do contexto que envolve o denominado meio ambiente físico laboral, que é subdividido em meio ambiente físico laboral estático e meio ambiente físico laboral móvel. O primeiro diz respeito à construção contida no imóvel destinado à atividade empresarial, ou seja, a empresa em si, estática, sendo o segundo referente ao maquinário utilizado no ambiente laboral, que pode ser mais facilmente modificado, como também pode ser objeto de deslocamento e descarte.

$\mathrm{E}$ a inserção do meio ambiente laboral como elemento inerente ao meio ambiente geral decorre de inúmeras premissas constitucionais, que de forma implícita ou expressa protegem 
o referido meio ambiente, bem como aquele que a ele pertence, ou seja, o trabalhador que se submete a determinadas condições de labor, muitas delas vinculadas ao ambiente físico no qual se insere e executa suas tarefas cotidianas.

Deve-se, portanto, apontar as normas contidas no artigo 1.-o, inciso III, da Constituição de 1988, que versa sobre o direito fundamental garantidor da dignidade da pessoa humana, diretamente vinculado ao que descreve o seu artigo $5 .^{\circ}$, inciso III, que veda a exposição do homem a tratamento desumano e condições degradantes.

Pode-se presumir, sem quaisquer controvérsias, a garantia de não submissão do ser humano a condições degradantes e prejudicais a seu labor e sua condição física e psíquica, sob todo e qualquer aspecto.

Harmonizando-se com o arcabouço normativo atinente aos Direitos Humanos, aqui apontado, cumpre também fazer referência ao disposto no artigo 6.. da Constituição da República de 1988, que indica como direito social a garantia da saúde ao trabalhador. Já o seu artigo 7..-, que enumera os diversos direitos inerentes ao trabalhador, inclusive aqueles de indisponibilidade absoluta, que visam a preservar a sua própria condição humana, dispõe em seu inciso XXII sobre a garantia da redução dos riscos inerentes ao trabalho, por meio das normas de saúde, higiene e segurança.

Há que se referir também, quanto ao capítulo referente aos princípios gerais da atividade econômica, a garantia de valorização do trabalho humano conjugado com a proteção ao meio ambiente, inclusive, de modo diferenciado, ante o impacto ambiental decorrente de determinada atividade econômica exercida, como revela o artigo 17o, inciso VI, da Constituição Federal.

E a proteção ao meio ambiente do trabalho se reflete no espaço físico no qual se insere a atividade econômica, sendo um dos pilares da função social da propriedade, insculpida no artigo 170, inciso III, da Constituição da República de 1988.

O reconhecimento do meio ambiente vinculado ao trabalho como uma das vertentes inerentes ao meio ambiente geral deriva expressamente do que prescreve o artigo 200, inciso VIII, da Constituição, ao apontar como responsabilidade do sistema único de saúde a colaboração com o meio ambiente, nele inserido o meio ambiente laboral.

E por fim deve-se apontar também o conteúdo do artigo 225 da Constituição da República, em seu capítulo destinado exclusivamente ao meio ambiente, com a inserção no ordenamento jurídico da garantia inerente a todo e qualquer cidadão a um meio ambiente ecologicamente equilibrado, além do dever do poder público em controlar os meios de produção no sentido de evitar danos à saúde, qualidade de vida e ao meio ambiente de modo geral, como disposto no inciso $\mathrm{V}$ do referido preceito legal.

A relevância do trabalho do ser humano na concepção do meio ambiente do trabalho como um direito fundamental é oportunamente resumida por Adelson Silva dos Santos, que dispõe o seguinte:

Assim, a Constituição que tem como um dos fundamentos da República a dignidade da pessoa humana e assegura a vida com qualidade, inclusive com direito a um meio ambiente ecologicamente equilibrado, não pode ser interpretada ou explicitada por outra lei para tolerar atividade que coloque em risco a vida, a integridade e a segurança dos cidadãos, entre estes, os trabalhadores.

Tendo a Constituição tratado o meio ambiente como um bem de todos, de proteção difusa, entre eles, o do trabalho, como já restou fundamentado, este deverá ter tutela jurídica específica, sem solução de continuidade com as outras dimensões do meio ambiente, com vista à proteção da saúde e do bem-estar do trabalhador, cujo conteúdo essencial, impassível de supressão, é a não danosidade irreversível à saúde e segurança física e psíquica do trabalhador (SANTOS, 2010, p. 112) 
Portanto, a proteção ao meio ambiente do trabalho deve abarcar todos os seus aspectos, inclusive, no que toca a preservar o bem no qual se insere o empreendimento, ou seja, o imóvel e os bens móveis que o compõe. Tal patrimônio, em conjunto, revela os bens da empresa e se constituem no já denominado meio ambiente físico do trabalho, cuja preservação tem por objeto também resguardar o próprio ser humano nele inserido, hipossuficiente, via de regra.

Daí se presumir que a propriedade possuir um significativo e relevante objeto no tocante às relações humanas, inclusive no que tange às questões inerentes aos contratos de trabalho, eis que nela se assentam o local da prestação de serviços e todo o seu maquinário e, a indevida utilização de tais bens, poderá imputar prejuízos irreparáveis ao homem.

A função sócio ambiental da propriedade emerge também como mandamento de salvaguarda, inclusive, no que concerne ao meio ambiente laboral e tal relevância será a seguir destacada.

\section{A FUNÇÃO SÓCIO AMBIENTAL DA PROPRIEDADE E A SUA CONSECUÇÃO PELO EMPREGADOR POSSUIDOR DIRETO}

O Código Civil Brasileiro consagra o direito de propriedade como a faculdade do titular de um bem em usar, gozar e dispor da coisa, bem como possui o direito de reavê-la de quem a possuir ou deter de maneira injusta.

Tal assertiva está consagrada no caput do artigo 1228 do referido sistema normativo. Todavia, o exercício de tais faculdades deve se amoldar e se harmonizar a diversos preceitos e princípios vigentes no ordenamento jurídico, de modo a se extrair da propriedade sua melhor utilidade e inserção na vida do homem.

Daí a concepção da existência de propósitos inerentes ao exercício do direito de propriedade, que se conjuga com princípios de ordem constitucional, com o da dignidade da pessoa humana, finalidade social, dentre outros.

A preservação do meio ambiente como direito fundamental de terceira geração interage com a disposição da propriedade, na medida em que esta guarda estrita vinculação com o denominado meio ambiente físico, seja ele natural ou artificial.

E em uma sociedade na qual se propõe a elevação da condição humana a patamares mais justos, equilibrados, minimizando-se as desigualdades sociais, o exercício do direito de propriedade também deve se harmonizar em face de tais aspectos.

Surge, portanto, como elemento inibidor do pleno e absoluto exercício de vontade em face da propriedade, em virtude de quaisquer um de seus poderes (usar, gozar e dispor), a necessidade de se atribuir a ela uma função social.

E referida característica emerge dos comandos constitucionais expressamente já referidos no capítulo anterior, em especial, ao que dispõe o artigo 170, inciso III, que consagra a necessidade de se conferir à propriedade, sob um aspecto amplo, a sua função social.

Aludida concepção nasce da teoria apresentada por Leon Duguit, ainda no século XIX. Assim dispõe o jurista acerca da existência da função social da propriedade:

(...) todo individuo tiene la obligación de cumplir em la sociedad uma cierta función em razón directa del lugar que em ella ocupa. Ahora bien, el possedor de la riqueza, por lo mismo que posee la riqueza, puede realizar um cierto trabajo que solo el puede realizar. Sólo el puede aumentar la riqueza general haciendo valer el capital que posee. Está, pues, obligado socialmente a realizar esta tarea, y no será protegido socialmente más que si la cumple y em la medida que la cumpla. La propriedad no es, pues, El derecho 
subjetivo del proprietário; es la función social del tenedor de la riqueza. (DUGUIT, 1975, p.240) $)^{3}$

E sobre referida característica que coercitivamente, pela via constitucional, deverá recair sobre a propriedade, assim dispõe Guilherme José Purvin de Figueiredo, abordando visão atual acerca do aludido princípio:

A efetividade do Direito no planejamento, controle e fiscalização das atividades econômicas que se processam em espaços privados depende da implementação de determinados princípios jurídicos que temperem a concepção liberal individualista do direito de propriedade. Considerando que o Direito Ambiental afeta o exercício do direito de propriedade, traçando seus contornos, depende ele de princípios aptos a atingir referidos objetivos, dentre os quais sobressai o da função social da propriedade. O cumprimento do princípio da função social da propriedade não se limita à consecução de uma finalidade social, vez que seu conteúdo deve contemplar a forma (os meios) para se alcançar tal finalidade.

O princípio da função social da propriedade tampouco significa mero estabelecimento de limitações ao exercício do direito de propriedade, ou de imposições negativas ao comportamento do proprietário, não obstante as regras sobre o uso ambientalmente responsável da propriedade resultem da efetividade desse princípio. (FIGUEIREDO, 2010, p.32-33)

Relevante também apontar a concepção trazida por Daniela Oliveira Gonçalves e Elcio Nacur Rezende, no tocante à função sócio ambiental da propriedade:

Dos estudos realizados, pode-se concluir que a função socioambiental atualmente se apresenta basicamente sob três aspectos: econômico (produtividade), social (bemestar dos proprietários e trabalhadores e direitos trabalhistas) e ambiental (utilização adequada dos recursos naturais e preservação do meio ambiente). Não basta que a propriedade seja produtiva. Ela também deve cumprir os demais requisitos impostos pela lei, sob pena de desapropriação para fins de reforma agrária. (GONÇALVES, REZENDE, 2015, p.69)

A relação indissociável entre função social e os direitos inerentes ao exercício da propriedade também é objetivamente apresentada por Cristiano Chaves de Farias e Nelson Rosenvald:

\begin{abstract}
A locução função social traduz o comportamento regular do proprietário, exigindo que ele atue numa dimensão na qual realize interesses sociais, sem a eliminação do direito privado do bem que lhe assegure as faculdades de uso, gozo e disposição. Vale dizer, a propriedade mantém-se privada e livremente transmissível, porém detendo finalidade que se concilie com as metas do organismo social. (FARIAS, ROSENVALD, 2018, p.320)
\end{abstract}

E é certo que referida característica se insere nas relações de trabalho e em todos os atos e relações jurídicas a ela conexas. Portanto, o imóvel no qual se assenta o empreendimento deve ser resguardado no sentido de não se transformar em instrumento de degradação do meio ambiente laboral, sob pena de se responsabilizar o causador do dano, cabendo-lhe também inserir-se em sua função social.

De tal modo, ainda que não seja proprietário do imóvel destinado ao exercício da atividade econômica, o empregador locatário ou arrendatário tem plena responsabilidade em resguardar o bem do qual é possuidor direto, não podendo ser transformado, seja o local

3 Todo indivíduo tem a obrigação de cumprir uma determinada função na razão direta do lugar que ocupa na sociedade. Agora, o possuidor de riqueza, pela mesma razão que possui riqueza, pode fazer um certo trabalho que somente ele pode fazer. Somente ele pode aumentar a riqueza geral afirmando o capital que possui. Ele é, portanto, socialmente obrigado a executar essa tarefa e não será protegido socialmente, exceto se o fizer e na medida em que o fizer. A propriedade não é, portanto, o direito subjetivo do proprietário; é a função social do detentor da riqueza. (tradução nossa) 
onde se situa a empresa, seja o maquinário nele inserido, em instrumentos de degradação ambiental, seja sob o aspecto geral, seja no que concerne à submissão dos trabalhadores a condições nocivas e degradantes de sua saúde física e mental.

Como já apontado, é presumível o direito fundamental dos trabalhadores em estarem submetidos a ambiente laboral digno, saudável, equilibrado, que lhes permita o exercício natural de sua atividade profissional, absolutamente afastados do risco de acidentes e doenças ocupacionais.

E a função social da propriedade surge também como elemento de afirmação do meio ambiente laboral como sujeito de máxima proteção, bem como todos que nele se inserem, revelando, portanto, um direito fundamental de terceira geração.

Sendo o empregador proprietário ou tão somente titular de posse direta, decorrente, por exemplo, de contratos de arrendamento ou locação, o dever de preservar o bem no qual se insere o empreendimento, com a finalidade maior de preservar aquele que mais a ele se submete, quem seja, o trabalhador, é obrigação absoluta. Torna-se, pois, passível de repreensão, conforme se depreende do que dispõe o artigo 225, §3.․, da Constituição Federal de 1988, que dispõe as "as condutas e atividades consideradas lesivas ao meio ambiente sujeitarão os infratores, pessoas físicas ou jurídicas, a sanções penais e administrativas, independentemente da obrigação de reparar os danos causados".

De tal modo, a lesão ao meio ambiente sujeita o infrator a múltiplas sanções, tanto de natureza criminal, como de natureza administrativa, junto ao poder público, além daquela inerente à reparação do dano.

Vale dizer que a função sócio ambiental aqui referida diz respeito à preservação do meio ambiente do trabalho, bem como a reunião de esforços para oferecer um ambiente sadio, equilibrado, que permita aquele que habita, ou seja, o trabalhador, de usufruir de um espaço físico lúdico, agradável, permitindo o exercício prazeroso, não estafante, de sua atividade laborativa cotidiana.

Assim, a degradação ambiental não pode atingir também o meio ambiente do trabalho, conclusão essa objetivamente extraída do pensamento de Jacopo Paffarini, Mariângela Matarazzo Fanfa Colognese e Eduardo Henrique Hamel:

A urgência ambiental exigiu a adequação a uma nova realidade. Nas últimas décadas uma atenção sem precedentes foi projetada na conscientização de que a degradação ambiental poderia efetivamente ameaçar a sobrevivência de todas as formas de vida no planeta. (Paffarini, Colognese e Hamel, 2017, p.58)

E a não observância pelo empregador, seja ele mero possuidor direto (não proprietário), seja ele proprietário, o sujeita a sanções das mais diversas espécies, cuja aferição, regra geral, independe de se perquirir sua culpa, ante a adoção majoritária da teoria objetiva da responsabilidade civil, inclusive quanto ao risco integral, seja pela doutrina, seja pela jurisprudência atual.

Todavia, no capítulo que se segue será analisado o aspecto fático jurídico concernente à hipótese se referida teoria poderia ser aplicada ao proprietário possuidor indireto, tendo em vista eventual lesão ao meio ambiente do trabalho, derivada do espaço físico (móvel ou imóvel) destinado à atividade empresarial, especialmente no que toca à lesões de ordem coletiva vivenciada pelos trabalhadores. 


\section{A RESPONSABILIDADE DO PROPRIETÁRIO (POSSUIDOR INDIRETO) PELA REPARAÇÃO DOS DANOS INERENTES AO MEIO AMBIENTE LABORAL DEGRADADO}

O risco ambiental é inerente à exploração do homem ao meio ambiente que o cerca. E aludida exploração, ao longo das décadas, tornou-se cada vez mais sofisticada, intensiva e também incisiva, potencializando os riscos ao meio ambiente sob diversos aspectos, bem como aquele nele inserido, ou seja, o homem.

O ser humano mergulhou, ao longo dos anos, em um complexo emaranhado tecnológico de produção de riscos, que muitas vezes, silenciosamente, o acaba envolvendo, tornando-o ao mesmo tempo o causador e destinatário dos riscos. Veja-se, portanto, o pensamento do sociólogo alemão Ulrich Beck:

Contido na globalização, e ainda assim claramente distinto dela, há um padrão de distribuição de riscos no qual se encontra um material politicamente explosivo: cedo ou tarde, eles alcançam inclusive aqueles que o produziram ou que lucraram com eles. Em sua disseminação, os riscos apresentam socialmente um efeito bumerangue: nem os ricos e poderosos estão seguros diante deles. Os anteriormente "latentes efeitos colaterais" rebatem também sobre os centros de sua produção. Os atores da modernização acabam, inevitável e bastante concretamente, entrando na ciranda dos perigos que eles próprios desencadeiam e com os quais lucram. Isso pode ocorrer de diversas formas. (BECK, 2011, p.44)

E referida produção de riscos, com toda sua complexidade e alcance, também se estende ao chamado meio ambiente laboral, na medida em que o empregador dirige sua atividade empresarial, com objetivo específico de obtenção de ganhos econômicos, ou seja, de gerar e expandir suas riquezas, fato que gera um efeito inversamente proporcional, qual seja, a potencialização dos riscos derivados da atividade econômica que exerce.

É de se presumir que os riscos de uma determinada atividade empresarial são geridos pela própria empresa, ou seja, por quem exerce tal atividade, que possui e projeta toda a dimensão de sua exploração econômica. Quanto à denominada "gestão do risco", assim definem Carla Reita Faria Leal e Solange de Holanda Rocha:

\footnotetext{
A gestão do risco consiste no processo que inclui seleção e implementação das medidas preventivas e protetivas mais apropriadas, tomando por base os resultados do processo de avaliação de risco, do controle tecnológico disponível, da análise de custo e benefício e custoefetividade, do risco aceitável, e preocupações com possíveis impactos ambientais. (Leal, Carla Reita Faria; Rocha, Solange de Holanda. Riscos Ambientais Laborais na Sociedade Global e sua Proteção Jurídica. Veredas do Direito, Belo Horizonte, v.15, n.33, p.271, set./dez. 2018. http://www.domhelder.edu.br/revista/index.php/veredas/ article/view/1151/24637)
}

Citam ainda, ainda, as referidas autoras, a existência de competência destinada ao Ministério do Trabalho em editar normas complementares para a aplicação das normas gerais contidas na Constituição da República, cabendo ao empregador a obediência rígida quanto a tais regramentos, sob pena de sofrerem sanção de ordem administrativa, como multas, além da possibilidade de se gerar danos aos trabalhadores submetidos a um meio ambiente de trabalho viciado, danos esses reparáveis por ações de cunho individual ou coletivo, visando a reparação civil.

De tal modo, veja-se: 
Por outro lado, a legislação trabalhista brasileira [CLT, art. 155] conferiu ao Ministério do Trabalho competência para estabelecer normas complementares para aplicação dos preceitos legais, o que resultou, a partir da Portaria MTb no 3.214 , de 8 de junho de 1978, na aprovação das Normas Regulamentadoras [NRs], que foram redigidas principalmente com base nas diretrizes sobre saúde e segurança no trabalho emanadas pelas convenções da Organização Internacional do Trabalho [OIT].

Ainda nesse contexto, a NR-9 estabelece a obrigatoriedade da elaboração e implementação, por parte de todos os empregadores e instituições que admitam trabalhadores como empregados, do Programa de Prevenção de Riscos Ambientais [PPRA], visando à preservação da saúde e da integridade dos trabalhadores, através da antecipação, reconhecimento, avaliação e consequente controle da ocorrência de riscos ambientais existentes ou que venham a existir no ambiente de trabalho, tendo em consideração a proteção do meio ambiente e dos recursos naturais [item 9.1.1].

São considerados riscos ambientais laborais os agentes físicos, químicos, biológicos, ergonômicos e mecânicos existentes nos ambientes de trabalho que, em função de sua natureza, concentração ou intensidade e tempo de exposição, são capazes de causar danos à saúde do trabalhador. Em regra, a previsão dos riscos mecânicos e ergonômicos não é obrigatória no PPRA [item 9.1.5]. (Leal, Carla Reita Faria; Rocha, Solange de Holanda. Riscos Ambientais Laborais na Sociedade Global e sua Proteção Jurídica. Veredas do Direito, Belo Horizonte, v.15, n.33, p.272, set./dez. 2018. http://www. domhelder.edu.br/revista/index.php/veredas/article/view/1151/24637)

Percebe-se, portanto, a notória obrigação do empregador no que tange ao gerenciamento e coibição dos riscos. E, na medida em que o risco se materializa no dano, é dever absoluto do empregador, inclusive por assumir todos os ônus de sua atividade econômica, na forma contida no artigo $2 .$. da CLT, a reparar quaisquer danos alusivos ao meio ambiente do trabalho.

E no que toca à responsabilidade pelo dano ambiental, é cediço que tanto a doutrina prevalente, quanto a jurisprudência, adotam a teoria objetiva da responsabilidade pela degradação ambiental, prevalecendo ainda, a partir de tal entendimento, a teoria do risco integral, em relação ao qual não há espaço para excludentes de culpabilidade, bastando a ocorrência do evento danoso, para que haja a responsabilidade em face do agente causador da degradação ambiental. Nesse sentido, veja-se o entendimento de José Adércio Leite Sampaio:

Porque o riscoabsoluto ou integral deve ser preferidoàs outrasteorias da responsabilidade civil para o dano ambiental? Pelo objeto e direito envolvidos; pela necessidade de minimizar os efeitos da ideologia hegemônica da apropriação inesgotável[13]. Em sendo um bem transindividual, coletivo ou, na dicção constitucional, "de uso comum do povo", que integra o patrimônio indiviso das atuais e futuras gerações, sendo pressuposto, fonte e matriz da vida, nenhum dano que sofra poderá ficar sem reparação. (SAMPAIO, 2015, p.296)

Contudo, resta aqui ser debatida a eventual responsabilidade do proprietário, quando este não exerce a posse direta do imóvel, cedido, por exemplo, a título de arrendamento a um empreendedor, para que este execute sua atividade econômica e, partir de referida exploração, surjam danos ao meio ambiente laboral, especialmente em virtude da exposição dos trabalhadores a riscos à sua integridade física ou mental.

E isto se daria pela submissão dos empregados ao próprio ambiente físico no qual se instala o empreendimento, ou seja, sua edificação, bem como pelo manuseio das ferramentas (maquinário) ali inseridas.

A simples aplicação da teoria do risco integral, com atribuição de responsabilidade inclusive em face daquele que financeiramente se beneficiou do contrato de arrendamento, como o proprietário possuidor indireto, pode dar ensejo a situações fáticas que fogem a seu 
controle, podendo este ser imputado a reparar danos decorrentes de atos em relação aos quais não poderia sequer impedir, não tendo qualquer participação.

Daí se conceber, em tal caso específico, a possibilidade de não aplicação da teoria do risco integral, mas a utilização da teoria do risco criado, na medida em que não houve nenhuma participação ou mesmo ciência daquele que é tão somente o proprietário, sem se tratar de possuidor direto.

Corroborando com tal pensamento, veja-se o entendimento exarado por Clayton Reis, André Lipp Pinto Basto Lupi e Débora Cristina de Castro Rocha:

Apesar das constatações supra, certo ainda que não se revela possível imputar o dever de indenizar àquele que em nenhum momento concorreu para gerar o dano. Todavia, se faz imperiosa a necessidade de comprovar que o fato ocorreu independentemente da atitude do agente, por motivos alheios à sua vontade, não cabendo a ele a possibilidade de prever ou resistir. (REIS, LUPI, ROCHA, 2019, p.187)

Abre-se, pois, a possibilidade da excludente de responsabilidade quando determinado ente, como o proprietário possuidor indireto não tem qualquer participação ou possibilidade de previsão acerca da ocorrência dos eventos danos. Parece razoável aqui, deixar de imputar a ele qualquer responsabilidade, recaindo esta, diretamente e sob a ótica da responsabilidade civil objetiva pelo risco integral, tão somente ao arrendatário possuidor direto. Se aplicaria, portanto, ao proprietário, a teoria objetiva vinculada ao risco criado.

Contudo, caso o dano ao meio ambiente laboral tenha como causa o próprio estado ou mesmo a estrutura do denominado meio ambiente de trabalho físico, cumpre aqui verificar se há a participação do proprietário possuidor indireto na construção do meio ambiente de trabalho degradado.

Parte-se da premissa que, como objeto do arrendamento, esteja um imóvel com suas construções e maquinário, sendo estes explorados pelo empresário que venha a arrenda-lo sem qualquer alteração do referido meio ambiente físico. Assim, faz este uso da estrutura física do imóvel, em seu interesse empresarial, sem qualquer modificação, aproveitando também o maquinário contido no imóvel, bem como toda sua estrutura física, tal como lhe fora cedida por força do contrato de arrendamento.

E partindo-se do fato de que referida utilização causa danos ao meio ambiente laboral, em especial, aos trabalhadores nele inseridos, não seria possível a imputação de responsabilidade ao proprietário, responsável pelo surgimento do referido ambiente laboral degradado, já que era responsável pelo estado do imóvel, bem como de seu maquinário?

Daí se vislumbra a viabilidade da responsabilização, desde que haja a mínima participação do proprietário no evento danoso. Assim, concorrendo o proprietário para a consecução do dando, se caracterizaria esse também como ente poluidor, tendo que arcar com os ônus da reparação, aplicando ao caso o princípio do poluidor pagador. Sendo assim, veja-se o entendimento oriundo do pensamento de Danielle de Andrade Moreira, Letícia Maria Rêgo Teixeira Lima e Izabel Freire Moreira:

O princípio do poluidor-pagador, se efetivamente aplicado, funciona como um mecanismo de redução da poluição (MOREIRA, 2015b, p. 91). Sua completude se dá no momento em que, internalizados pelo poluidor, os custos de prevenção e reparação não recaiam sobre a coletividade e os danos sejam evitados. Assim, garante-se que haja responsabilidade por parte dos poluidores e, em consequência, promove-se o equilíbrio do mercado, a conscientização de produtores e consumidores, o estímulo a avanços tecnológicos e o fomento a atitudes preventivas mais sedutoras no contexto de precisa alocação de custos e responsabilidades. E, como consequência, espera-se que a aplicação do PPP promova a redução das iniquidades ambientais existentes num cenário 
de privatização de bônus e socialização de ônus. (Moreira Danielle de Andrade; Lima, Letícia Maria Rêgo Teixeira; Moreira. O Princípio do Poluidor Pagador na Jurisprudência do STF e DSTJ: Uma Análise Crítica. Veredas do Direito, Belo Horizonte, v.16 , n. 34, p.367-432, jan./abr. 2019. Disponível em: http://www.domhelder.edu.br/revista/index. php/veredas/article/view/1341/24736)

Outro questionamento que deriva de tal situação fática seria se, caso houvesse participação do proprietário no que concerne às degradantes condições de trabalho, poderia ser ele responsabilizado solidariamente com o empregador?

Pela conjugação das disposições legais vigentes, bem como a partir do entendimento doutrinário e jurisprudencial prevalentes, pode-se aferir a responsabilidade solidária em relação a ambos. No caso do empregador, este é o responsável imediato e direto pela manutenção de um meio ambiente do trabalho sadio e equilibrado, aplicando-lhe a teoria objetiva aliada ao risco integral. Já no tocante ao proprietário possuidor indireto, como, por exemplo, o arrendador de um imóvel destinado a receber um empreendimento, que cede por força de um contrato o imóvel onde se situa a empresa e, muitas vezes, além disso, também o maquinário, ou parte dele, também é responsabilizado, mas deve-se ressalvar aqui a possibilidade de exclusão de sua culpa, por meio de prova do qual teria o ônus.

Assim, poderia demonstrar a inexistência de qualquer vinculação com eventuais danos causados ao meio ambiente laboral.

Contudo, em caso de contribuição para o evento danoso, é viável atribuir-lhe responsabilidade solidária, a partir da interpretação do que dispõe o artigo 14, § 1.o, da Lei 6.938/81 (Lei de Política Nacional do Meio Ambiente), que versa expressamente acerca da atribuição de responsabilidade do poluidor em reparar o dano por ele causado, independentemente da existência de culpa, estando legitimado, inclusive, o Ministério Público legitimado a propor Ação Civil Pública nesse sentido. E harmonizando com tal dispositivo, cite-se o contido no artigo $3^{\circ} \cdot$, inciso IV, da referida lei, que conceitua o poluidor como a pessoa física ou jurídica responsável direta ou indiretamente pela atividade que gere degradação ao meio ambiente.

E invocando novamente o disposto no artigo 225, §3.‥ da Constituição Federal de 1988, este aduz acerca da responsabilização dos infratores, pessoas físicas ou jurídicas, a sanções penais e administrativas, além do dever de reparar os danos causados ao meio ambiente. Assim, referido texto traz um contexto plural, podendo-se presumir a responsabilização conjunta, ou seja, solidária, de todos aqueles que contribuíram para o evento danoso.

Veja-se, portanto, nesse sentido, o entendimento oriundo do pensamento de Clayton Reis, André Lipp Pinto Basto Lupi e Débora Cristina de Castro Rocha:

Extrai-se dos dispositivos legais supra a solidariedade da obrigação daqueles que infrinjam e poluam, denominados de devedores pelo dever de reparação do dano ambiental em prol da sociedade a quem denominados de credora. Diante disso, tem-se que, "tanto aquele que concorre diretamente para o desabrochar do dano como aquele cuja atividade, indiretamente, representa uma possível condição sem a qual ele talvez não tivesse ocorrido respondem solidariamente pela obrigação de repará-lo por inteiro". (REIS, LUPI, ROCHA, 2019, p.182-183)

Referido raciocínio é corroborado com o pensamento de Rut Gonzáles Hernández aqui descrito:

Cuando son varias las personas responsables del mismo daño es preciso determinar el régimen jurídico aplicable a la obligación de indemnizar. De la interpretación de los preceptos del Código Civil se puede concluir que la regla general es la mancomunidad y como excepción la solidaridad. 
La jurisprudencia más relevante se inclina a favor de la solidaridad, sobre todo cuando no es posible conocer que parte de daño es atribuible a cada causante. Esta cuestión es de especial dificultad y trascendencia en materia de daños al medio ambiente. (HERNÁNDEZ, 2012, p. 189) ${ }^{4}$

Assim, se todos aqueles contribuem, de alguma forma, com eventuais danos praticados ao meio ambiente do trabalho, poderiam sim, serem responsabilizados de forma direta, surgindo aí o dever de reparação do dano, ressalvada a possibilidade do proprietário não possuidor em demonstrar que não concorreu em nenhuma hipótese para o dano ocorrido.

Por conseguinte, em eventual ajuizamento de Ação Civil Pública, buscando reparações em favor de uma coletividade de trabalhadores, em virtude de danos ocasionados diretamente em face do meio ambiente do trabalho no qual se inserem, poderia o Ministério Público do Trabalho pretender a responsabilização do empregador, além do arrendador, ante os preceitos acima referidos.

\section{CONSIDERAÇÕES FINAIS}

A Constituição da República de 1988 referenda o acesso e preservação de um meio ambiente justo e ecologicamente equilibrado como um direito vinculado a universalidade, com alicerces que apontam a necessidade de uma proteção.

Daí ser concebido pela doutrina e jurisprudências nacionais como um direito fundamental de terceira geração.

E diante dessa concepção se percebe toda uma construção normativa derivada da Constituição Brasileira, no sentido de proteger o meio ambiente em todos os seus aspectos e alcance.

E um dos aspectos inerentes ao meio ambiente geral se revela no meio ambiente do trabalho, também albergado por vasta e profunda proteção de natureza constitucional, no sentido de não só abarcar o ambiente laboral, mas também o indivíduo que nele se insere, ou seja, o trabalhador.

A proteção constitucional ao meio ambiente do trabalho alcança, sem sombra de dúvidas, todos os aspectos a ele inerentes, seja no que concerne ao meio ambiente físico, seja no que diz respeito ao meio ambiente imaterial.

Quanto ao primeiro, objeto central desse estudo, este se subdivide em meio ambiente físico estático (imóvel), sendo este a construção na qual se desenvolve a atividade econômica do empregador, bem como também no denominado meio ambiente físico móvel, que se revela no maquinário inserido no estabelecimento, que poderá ser deslocado ou descartado.

Em virtude de todo o sistema constitucional que protege o meio ambiente, surge o dever de conservação e salvaguarda do meio ambiente do trabalho. Assim, seja o empregador o proprietário do bem (construção) no qual se situa seu empreendimento, seja ele mero possuidor direto não proprietário, possui ele o dever absoluto de zelar pela conservação e melhoria do referido espaço físico, sujeitando-se ao dever de reparar eventual dano que tenha dado causa ou concorrido, no que toca ao meio ambiente do trabalho e aqueles nele inseridos, quais sejam, os trabalhadores.

4 Quando existem várias pessoas responsáveis pelos mesmos danos, é necessário determinar o regime legal aplicável à obrigação de indenizar. A partir da interpretação dos preceitos do Código Civil, pode-se concluir que a regra geral é a comunidade e, como exceção, a solidariedade.

A jurisprudência mais relevante se apóia em favor da solidariedade, principalmente quando não é possível saber que parte do dano é atribuível a cada causa. Esse problema é de especial dificuldade e importância em termos de danos ao meio ambiente. (tradução nossa) 
Uma vez consagrada a teoria objetiva quanto ao risco integral, no que concerne à reparação do dano ambiental, esta também alcançaria o empregador, responsável direto pelo meio ambiente físico do trabalho.

Todavia, cumpre verificar a existência de eventual responsabilidade no que concerne ao proprietário, possuidor indireto, como nos casos de locação ou arrendamento, tendo em vista os danos havidos ao meio ambiente do trabalho.

Respondendo aos problemas expostos no estudo em questão, se verifica a hipótese de se atribuir responsabilidade para a reparação de danos inerentes ao meio ambiente físico do trabalho, inclusive ao proprietário que não dirige a atividade econômica, mas que dela se beneficia por meio de contrato de locação ou arrendamento.

Contudo, surgindo como exceção à teoria do risco integral, aludida responsabilidade deriva da participação, direta ou indireta, do referido proprietário, na concretização do dano ocorrido.

Assim, caso tenha cedido, por meio de contrato, um ambiente físico de trabalho já degradado ou com maquinário sujeito a degradação, sua responsabilidade é aferível, desde que se verifique sua concorrência com os motivos que desaguaram na ocorrência do dano.

E tal responsabilidade, ainda que não derive dos preceitos inerentes à teoria do risco integral, revela, como bem assentado na doutrina aqui destacada, tendo em vista a conjugação de preceitos legais vigentes, a possibilidade de se atribuir responsabilidade solidária entre o empregador arrendatário e o proprietário arrendador.

Reitera-se que a proteção ao meio ambiente justo, equilibrado, saudável, inclusive no que se refere ao ambiente de trabalho físico, estático ou móvel, emerge de um direito de ordem pública, indisponível, fundamental.

Portanto, não somente o empregador não proprietário responderia perante os lesados acerca do dano havido, mas também aquele possuidor indireto, que degradou a edificação ou maquinário cedida por contrato a um terceiro, lesando uma coletividade de trabalhadores.

Cabe, inclusive, ao Ministério Público do Trabalho o dever de, conforme o caso, ajuizar Ação Civil Pública no sentido de buscar a reparação dos danos causados à saúde e segurança dos trabalhadores submetidos a ambientes laborais degradados, seja por culpa do empregador, responsável direto e natural pela sua manutenção, seja pelo proprietário, possuidor indireto.

Por todo o exposto, sem olvidar da dignidade da pessoa do trabalhador, todavia, em homenagem ao conceito de Justiça em sua meta-juridicidade filosófica, bem como, aos princípios basilares do direito, calcados na demonstração do nexo causal como elemento indispensável à imputação de responsabilidade civil, atribuir ao possuidor indireto o dever de responder por um lamentável meio ambiente laboral degradado, sob pena de se querer, equivocadamente, apenar aquele que sequer, minimamente, contribui para um resultado que todos abominamos.

\section{REFERÊNCIAS BIBLIOGRÁFICAS}

BECK, Ulrich. Sociedade de Risco: rumo a uma outra modernidade; tradução de Sebastião Nascimento, 1. ed. São Paulo: 34, 2010, 304p.

BRASIL. Constituição (1988). Constituição da República Federativa do Brasil. Brasília: Senado Federal, Centro Gráfico, 1988. 
BRASIL. Lei 6.938, de 31 de Agosto de 1981. Dispõe sobre a Política Nacional do Meio Ambiente, seus fins e mecanismos de formulação e aplicação, e dá outras providências. Disponível em < http://www. http://www.planalto.gov.br/ccivil_03/LEIS/L6938.htm>. acesso em 27 set. 2019.

BRASIL. Lei n. 10.406, de 10 de janeiro de 2002. Institui o Código Civil Disponível em .<http:// www.planalto.gov.br/ccivil_03/LEIS/2002/L10406.htm>. Acesso em 26 set. 2019.

CASSAR, Vólia Bomfim. Direito do Trabalho. 16. ed. Rio de Janeiro: Forense, 2018, 1372p.

DUGUIT, Leon. Las transformaciones del derecho publico y privado. Buenos Aires: Heliasta, 1975.

FARIAS, Cristiano Chaves de; ROSENVALD, Nelson. Curso de Direito Civil: Reais. 14. ed. Salvador: JusPodivm, 2018, 1072p.

FELICIANO, Guilherme Guimarães; URIAS, João; MARANHÃO, Ney; SEVERO, Valdete Souto (Coord.). Direito Ambiental do Trabalho: Apontamentos para uma teoria geral. Vol.2. São Paulo: LTr, 2015, 581 p.

FIGUEIREDO, Guilherme José Purvin de. A propriedade no Direito Ambiental. 4. ed. São Paulo: Editora Revista dos Tribunais, 2010, 384 p.

FIORILLO, Celso Antônio Pacheco. Curso de direito ambiental brasileiro. 7. Ed., São Paulo: Saraiva, 2006.

GONÇALVES, Daniela Oliveira; REZENDE, Elcio Nacur. Função socioambiental da propriedade: a busca por uma determinação pragmática de aferição de cumprimento. Revista da Faculdade de Direito-FRD-UERJ. Rio de Janeiro, n.28, p. 52-72, dez.2015. Disponível em: https://www.epublicacoes.uerj.br/index.php/rfduerj/article/view/10597/14646

HERNÁNDEZ, Rut Gonzáles. La responsabilidad civil por daños al medio ambiente. Anuario Jurídico y Económico Escurialense. Madrid, n.45, p.177-192, ISSN: 1133-3677, 2012. Disponível em: https://dialnet.unirioja.es/servlet/articulo?codigo=3866244

LEAL, Carla Reita Faria; ROCHA, Solange de Holanda. Riscos Ambientais Laborais na Sociedade Global e sua Proteção Jurídica. Veredas do Direito, Belo Horizonte, v.15, n. 33, p.263-290, set./dez. 2018. Disponível em: <http://www.domhelder.edu.br/revista/index.php/ veredas/article/view/1151/24637>.

MOREIRA, Danielle de Andrade; LIMA, Letícia Maria Rêgo Teixeira; MOREIRA. O Princípio do Poluidor Pagador na Jurisprudência do STF e DSTJ: Uma Análise Crítica. Veredas do Direito, Belo Horizonte, v.16 , n. 34, p.367-432, jan./abr. 2019. Disponível em: http://www. domhelder.edu.br/revista/index.php/veredas/article/view/1341/24736

OLIVEIRA, Sebastião Geraldo. Proteção Jurídica à Saúde do Trabalhador. 4. ed. São Paulo: LTr, 2002, 526p. 
PADILHA, Norma Sueli. Do Meio Ambiente do Trabalho Equilibrado. São Paulo: LTr, 2002, 142p.

PAFFARINI, Jacopo; Colognese, Mariângela Matarazzo Fanfa; Hamel, Eduardo Henrique. A Insuficiência da Responsabilidade Socioambiental Empresarial na Perspectiva do Desenvolvimento Sustentável. Direito e Desenvolvimento, João Pessoa, v. 8, n., p. 55-75, dez. 2017. Disponível em: https://doi.org/10.25246/direitoedesenvolvimento.v8i2.541

PRATA, Marcelo Rodrigues. O Direito Ambiental do Trabalho Numa Perspectiva Sistêmica: As causas da inefetividade da proteção à ambiência laboral e o que podemos fazer para combate-la. São Paulo: LTr, 2013, 254p.

REIS, Clayton; LUPI, André Lipp Pinto Basto; ROCHA, Débora Cristina de Castro. Considerações sobre a responsabilidade civil solidária por dano ambiental. Revista Direito UFMS, Campo Grande, v.5, n. 1, p. 173-188, jan./jun. 2019.

SAMPAIO, José Adércio Leite. Teoria do Risco Ambiental Integral e Ideologia. Revista Internacional Consinter de Direito, Lisboa, ano I, no I, p. 283-302, 2oㅗ sem. 2015.

SAMPAIO, José Adércio Leite; WOLD, Chris; NARDY, Afranio. Princípios de direito ambiental: na dimensão internacional e comparada. Belo Horizonte: Del Rey, 2003, 304p.

SANTOS, Adelson Silva dos. Fundamentos do Direito Ambiental do Trabalho. São Paulo: LTr, 2010, 176p. 